\title{
Application of Chitosan In Vitro to Minimize the Adverse Effects of Salinity in Petunia $\times$ atkinsiana D. don
}

\author{
Marcelina Krupa-Małkiewicz ${ }^{1 *}$, NataliaFornal ${ }^{1}$ \\ 1 Department of Plant Genetics, Breeding and Biotechnology, West Pomeranian University of Technology in \\ Szczecin, Słowackiego 17 Str., 71-434 Szczecin, Poland \\ * Corresponding author's e-mail: mkrupa@zut.edu.pl
}

\begin{abstract}
The genus Petunia is a plant of high economic importance in the world-wide horticulture. These ornamental plants are often exposed to soil salinity that negatively affects their development. Chitosan is a biopolymer with multiple applications in plant breeding but it also minimizes the adverse effects of abiotic stresses on plant growth. The objective of this study was to investigate the effects of chitosan on petunia shoots development under salt stress in vitro. In the first experiment, four types of chitosan with molecular weight of $3.33,8,10$ and $970 \mathrm{kDa}$ in the concentrations of $0,10,15$ and $20 \mathrm{ppm}$ were supplemented into MS medium. In the second experiment, petunia shoots were grown on MS medium with the addition of different molecular weight of chitosan in the concentration of $15 \mathrm{ppm}$ each and $100 \mathrm{mM} \mathrm{NaCl}$. The results indicated that all of chitosan types and concentrations stimulate the plant growth in comparison to control. However, $15 \mathrm{ppm}$ chitosan concentration was more effective than other concentrations used. Salinity caused a significant reduction in shoot and root length, fresh and dry mass, plant water contents, while chitosan $(970 \mathrm{kDa})$ adjusted the salt toxicity. It is concluded that chitosan would be able to stimulate the growth of petunia shoots in vitro independent of their molecular weight. It was observed that the addition of chitosan of $970 \mathrm{kDa}$ to MS medium under salinity conditions may alleviate the inhibitory effect of salt stress on the plant growth.
\end{abstract}

Keywords: chitosan, micropropagation, petunia, salinity

\section{INTRODUCTION}

Tolerance to different abiotic stress and yield stability are complex genetic traits that are difficult to establish in many crops [Mahdavi and Rahimi, 2013]. Salinity is one of the abiotic factors that affects plant at every stage during development, vegetative growth, and yield production [AlTawaha and Al-Ghzawi, 2013; Mahdavi and Rahimi, 2013]. Salt stress has been showed to reduce the dry matter content, increase the root and shoot ratio, reduce the photosynthetic rate, transpiration rate, and cause degradation of chlorophyll [Manchanda and Garg, 2008; Khalid et al., 2015; Piwowarczyk et al., 2016; Krupa-Małkiewicz et al., 2017]. However, plants exhibit a broad spectrum of responses to salinity, but most of them have re- duced growth by salt [Piwowarczyk et al., 2016]. A fundamental biological understanding and knowledge of the effects of salt stress on plants is necessary to provide additional information for the identification of the plant response to salinity and try to find future applications for ameliorating the impact of salinity on plants. Proper selection of tolerant genotypes from the cultivated plants depends on the availability of verified assessment method. The conventional plant breeding strategy for overcoming the negative effects of salt stress has still limited success [Rai et al., 2010; Gaswanto et al., 2016]. One of the possible strategies for plants under saline conditions is the application of plant growth-regulating compounds that could alleviate the salt stress effect. Elicitors may be used in order to achieve the optimal growth 
of many crops under adverse conditions. In order to activate the defense responses, these molecules induce plant defense mechanisms through perception and transduction of biological signals [Angelova et al., 2006; Lizárraga-Paulin et al., 2011]. In order to minimize the adverse effects of salinity stress on plant growth, yield as well as biochemical and physiological processes, the exogenous application of plant growth regulators and elicitors has been used successfully [Bassuony et al., 2008; Sadak et al., 2010; Abdelhamid et al., 2013; Pongprayonn et al., 2013; KrupaMałkiewicz et al., 2015, 2016].

According to Mahdavi and Rahimi [2013] one of the methods to decrease the negative effect of abiotic stress is the application of chitosan. Chitosan is a biopolymer that is completely safe for the environment. This compound is a derivative of chitin and is characterized by biodegradability, bioactivity, and biocompatibility properties [Dias et al., 2013]. The molecules consitute oligosaccharides and biopolymers found in the cell walls of some fungi [Lizárraga-Paulin et al., 2011]. The main source of chitosan production is the chemical or enzymatic chitin deacetylation. According to Jabeen and Ahmad [2013] antioxidant activities of chitosan depend on the molecular weight as well as on the degree of deacetylation. It was also confirmed from various studies that the use of chitosan influences the increase in the yield in production, including floral production, and induces a range of metabolic changes, as a result of which plants become more tolerant to the abiotic and biotic factors [El-Hadrami et al., 2010; Lizárraga-Paulin et al., 2011; Jabeen and Ahmad, 2013; Pongprayonn et al., 2013]. However, there is variation between plants in their response to a given chitosan type and concentration [Pongprayonn et al., 2013)].

Petunia $\times$ atkinsiana $\mathrm{D}$. don belongs to Solanaceae family and is often considered a secondary plant model-system, due to various favorable biological features. These constitute common flowering ornamental plants, largely produced for home-consumption and for gardening [Berenschot et al., 2008].

The aim of this work was to investigate whether the application of different types and concentrations of chitosan at the in vitro culture can stabilize plant tolerance to salinity in Petunia $\times$ atkinsiana D. don.

\section{MATERIAL AND METHODS}

\section{Plant material and general experimental conditions}

Two separate experiments were conducted in the laboratory of the Department of Plant Genetics, Breeding and Biotechnology at the West Pomeranian University of Technology in Szczecin, Poland at 2016.

In the first stage of the study, chitosan concentration with the most favorable effect on the morphological characters of the tested petunia plants was selected. The plants material consisted of 15-20 mm shoots of Petunia $\times$ atkinsiana D.don "Prism White" obtained from sterile stabilized in vitro culture. The explants were multiplied on the MS medium according to Murashige and Skoog [1962] composition of macro- and microelements, $3 \%(\mathrm{w} / \mathrm{v})$ sucrose (Chempur, Poland), $0.8 \%(\mathrm{w} / \mathrm{v})$ agar (Biocorp, Poland) and 100 $\mathrm{mg} \cdot \mathrm{dm}^{-3}$ myo-inositol (Duchefa, Netherlands). After 35 days, shoots cuttings were placed on MS medium supplemented with chitosan of four different molecular weight $(3.33 ; 8 ; 10$ and $970 \mathrm{kDa})$ each in different concentration $(0,10,15$ and 20 ppm). Chitosan was added to the MS medium before autoclaving. MS medium without addition of chitosan was the control. After 28 days, shoot and root length, number of new shoots and fresh mass were measured. Dry mass of explants was determined after drying in the hot-air oven at $70^{\circ} \mathrm{C}$ for 24 hours. Plant Water Content (PWC \%) was determined following the formula:

$$
\begin{gathered}
\text { PWC }(\%)=\text { Fresh Mass }- \\
-(\text { Dry Mass/Fresh Mass }) \times 100
\end{gathered}
$$

The second experiment was conducted to establish the effects of the optimal concentration of chitosan on the morphological growth parameters of petunia plants under the salt stress. The explants treated with chitosan in vitro and also untreated plants were transferred to the MS medium with addition of $100 \mathrm{mM} \mathrm{NaCl}$ with or without 15 ppm of different types of chitosan $(3.33 ; 8 ; 10$ and $970 \mathrm{kDa}$ ). MS medium without addition of $\mathrm{NaCl}$ salt and chitosan was the control. After 28 days, the morphological traits (shoot and root length, number of new shoot, fresh and dry mass) as well as plant water content and electrical conductivity (EC\%) were determined.

The $\mathrm{pH}$ of all media was adjusted to 5.8. Culture jars $(300 \mathrm{ml})$ with the medium $(30 \mathrm{ml})$ 
were autoclaved for 20 minutes at $121{ }^{\circ} \mathrm{C}$ and $0.1 \mathrm{MPa}$. Sample size was four explants per culture vessel with eight replicates per treatment. All cultures were incubated in growth room at a temperature of $25^{\circ} \mathrm{C}$ under 16 hours photoperiod with a photosynthetic photon flux density (PPFD) of $40 \mu \mathrm{mol} \cdot \mathrm{m}^{-2} \cdot \mathrm{s}^{-1}$.

\section{Estimation of electrical conductivity}

Leaf disc of $1 \mathrm{~cm}^{2}$ were washed with distilled deionized water and placing in a test tube containing $10 \mathrm{ml}$ distilled water and incubated at $25^{\circ} \mathrm{C}$ on shaker (100 rpm) for 24 hours. At the end on incubation the electrolytic conductivity I (EC I) of bathing solution was recorded (Electrical Conductivity Meter). The samples were autoclaved at $121^{\circ} \mathrm{C}$ for 19 minutes and afterwards cooled to the room temperature EC II. Electrical conductivity was measured according the formula:

$$
\mathrm{EC}(\%)=(\mathrm{ECI} / \mathrm{ECII}) \times 100
$$

\section{Chitosan}

Four types of chitosan molecules (of molecular weight: $3.33 ; 8 ; 10$ and $970 \mathrm{kDa}$ ) were obtained from Center of Bioimmobilisation and Innovative Packaging Materials at West Pomeranian University of Technology in Szczecin, Poland. The products have been obtained according to Bartkowiak (2001).

\section{Statistical analysis}

The results obtained for plants in in vitro cultures were analysed statistically. The significance of differences was determined by means of variance analysis (ANOVA) and Tukey's test, at the level of significance of $\alpha=0.05$.

\section{RESULTS AND DISCUSSION}

\section{Effect of chitosan on in vitro growth of petunia explants}

The application of chitosan in vitro resulted in improved shoot and root length of petunia plants propagated in in vitro culture (Table 1). The highest shoot length $(4.69 \mathrm{~cm})$ was formed by Petunia explants grown on the MS medium supplemented with $8 \mathrm{kDa}$ chitosan in comparison to $3.33,10$, and $970 \mathrm{kDa}$ (by $9 \% ; 12 \% ; 26.4 \%$, respectively).
Out of all the chitosan concentrations applied in the experiment, $10 \mathrm{ppm}$ was found to be the most efficient in the stimulation of shoot length (Table 1). A different interaction was observed between the molecular weight of chitosan and its concentration. It was observed that higher concentration of chitosan had a negative effect on the length of the shoot. However, the polymer did not have a favorable effect on shoot formation and the number of petunia leaves. The number of shoots and leaves formed per one plant was lower than in the control independently of the used chitosan type and concentration (Table 1). The root length exhibited a dose-dependent effect to chitosan (Table 1). Compared to the control plants (grown on MS medium without the addition of chitosan), the maximal root length was obtained at $15 \mathrm{ppm}$ concentration of $8 \mathrm{kDa}$ chitosan (by $66.4 \%$ ). Furthermore, the application of $10 \mathrm{kDa}$ chitosan at concentration of $15 \mathrm{ppm}$ also increased the root length by $28.7 \%$ in comparison to control. In the case of addition of chitosan with the molecular weight of 3.33 or $970 \mathrm{kDa}$ to the medium, it was observed that along with the increase in concentration, the length of petunia roots decreased. Chitosan had significant effects on fresh weight, and the effects were dose dependent (Table 2). Out of all the concentrations applied, $15 \mathrm{ppm}$ resulted in the greatest increase in fresh weight and plant water contents (by $48.8 \%$ and $68.3 \%$, respectively) compared with the control. However, no statistical influence of chitosan and its concentration on dry weight of petunia plants was observed.

The relevant literature demonstrates that the addition of chitosan to the medium has a variable influence on morphology of different plant species. Ait Barka et al. [2004], who used chitogel for the stimulation of growth of grapevine in vitro, determined that the concentrations of over $2 \%(\mathrm{v} / \mathrm{v})$ had a negative effect on plant growth, based on shoot-length measurements, inducing even plant health. Sopalun et al. [2010] suggested that chitosan promoted in vitro shoot formation of Grammatophyllum speciosum but not rooting. On the contrary, Obsuwan et al. [2010b] described the stimulating effect of chitosan on the morphology of Rhynchostylis giganteaprotocorms propagated in vitro. Similarly to the present study, Obsuwan et al. [2010a] described the observations and stated that the polymer does not influence the height and the number of leaves of Dendrobium 'Eia Sakul'. In the current study, the optimal concentration of chitosan, allowing the best growth 
of petunia plants, was $15 \mathrm{ppm}$. Independently of the molecular weight of the used chitosan, the mean root length and the mean number of new shoots and leaves per explant, as well as fresh weight and the percentage water content, were enhanced (Table 1, 2). This concentration was used in subsequent experiments.

\section{Effect of chitosan on morphological traits of petunia exposure to salt stress}

The application of $100 \mathrm{mM} \mathrm{NaCl}$ salt into the MS medium had a negative effect on the morphological traits such as shoot and root length (Table 3). The petunia plants from MS medium supplemented with $100 \mathrm{mM} \mathrm{NaCl}$ were lower from the control plants by $69 \%$ and had $97.6 \%$ shorter roots. However, no statistically significant differences in the number of shoots formed per plant were observed. The obtained results are consistent with those observed by Jones [1986] and Krupa-Małkiewicz et al. [2016], who found that the salt concentration that is above $100 \mathrm{mM}$ in the medium has an inhibitory effect on seeds' germination and plant growth. In the present study, the growth characteristic of petunia explants under salinity stress was effectively improved with chitosan supplement. It was observed that the use of chitosan with the molecular weight of 970 $\mathrm{kDa}$ was the best to minimize the adverse effect of $\mathrm{NaCl}$ salt. The plants on MS medium with addition of $100 \mathrm{mM} \mathrm{NaCl}$ and $970 \mathrm{kDa}$ chitosan in concentration of $15 \mathrm{ppm}$ were taller by $19 \%$ and had $1575 \%$ longer roots than plants from MS medium supplemented with $100 \mathrm{mM} \mathrm{NaCl}$ salt (Table 3). The number of new shoots on the explant was equal to the control. According to many authors [Munns, 2005; Queirós et al., 2007; Man-

Table 1. Effect of different types and concentrations of chitosan on shoot and root length (cm) and number of new shoot and leaves of petunia 'Prism White' in vitro

\begin{tabular}{|c|c|c|c|c|c|}
\hline \multirow[t]{2}{*}{ Chitosan (A) } & \multicolumn{4}{|c|}{$\begin{array}{c}\text { Concentration (B) } \\
(\mathrm{ppm})\end{array}$} & \multirow[t]{2}{*}{ Mean } \\
\hline & 0 & 10 & 15 & 20 & \\
\hline \multicolumn{6}{|c|}{ Shoot length $(\mathrm{cm})$} \\
\hline $\mathrm{CH}_{3.33 \mathrm{kDa}}$ & 4.28 & 4.91 & 4.42 & 3.59 & 4.30 \\
\hline $\mathrm{CH}_{8 \mathrm{kDa}}$ & 4.20 & 5.16 & 5.08 & 4.26 & 4.69 \\
\hline $\mathrm{CH}_{10 \mathrm{kDa}}$ & 4.25 & 5.15 & 3.59 & 3.75 & 4.19 \\
\hline $\mathrm{CH}_{970 \mathrm{kDa}}$ & 4.22 & 4.31 & 3.40 & 2.84 & 3.71 \\
\hline Mean & 4.23 & 4.88 & 4.12 & 3.61 & \\
\hline $\mathrm{LSD}_{\mathrm{a}=0.05}$ & \multicolumn{5}{|c|}{$A=0.85 \quad B=0.91 \quad A \times B=n s^{*}$} \\
\hline \multicolumn{6}{|c|}{ Number of new shoots per plant } \\
\hline $\mathrm{CH}_{3.33 \mathrm{kDa}}$ & 3.0 & 1.18 & 1.06 & 1.0 & 1.56 \\
\hline $\mathrm{CH}_{8 \mathrm{kDa}}$ & 3.0 & 1.43 & 2.62 & 1.56 & 2.15 \\
\hline $\mathrm{CH}_{10 \mathrm{kDa}}$ & 2.75 & 1.81 & 1.37 & 1.43 & 1.84 \\
\hline $\mathrm{CH}_{970 \mathrm{kDa}}$ & 2.93 & 1.62 & 1.87 & 1.18 & 1.90 \\
\hline Mean & 2.92 & 1.51 & 1.73 & 1.29 & \\
\hline $\mathrm{LSD}_{\alpha=0.05}$ & & & $B=0.41$ & $A \times B=1.55$ & \\
\hline \multicolumn{6}{|c|}{ Root length $(\mathrm{cm})$} \\
\hline $\mathrm{CH}_{3.33 \mathrm{kDa}}$ & 7.56 & 4.34 & 2.18 & 1.76 & 3.96 \\
\hline $\mathrm{CH}_{8 \mathrm{kDa}}$ & 5.93 & 5.06 & 9.87 & 5.9 & 6.69 \\
\hline $\mathrm{CH}_{10 \mathrm{kDa}}$ & 7.06 & 3.75 & 9.09 & 3.59 & 5.87 \\
\hline $\mathrm{CH}_{970 \mathrm{kDa}}$ & 5.37 & 5.0 & 4.06 & 3.09 & 4.38 \\
\hline Mean & 6.48 & 4.53 & 6.30 & 3.58 & \\
\hline $\mathrm{LSD}_{\mathrm{a}=0.05}$ & \multicolumn{5}{|c|}{$A=1.71 \quad B=1.81 \quad A \times B=6.82$} \\
\hline \multicolumn{6}{|c|}{ Number of leaves per plant } \\
\hline $\mathrm{CH}_{3.33 \mathrm{kDa}}$ & 19.56 & 9.18 & 11.31 & 5.12 & 11.29 \\
\hline $\mathrm{CH}_{8 \mathrm{kDa}}$ & 18.18 & 10.37 & 12.0 & 11.5 & 13.01 \\
\hline $\mathrm{CH}_{10 \mathrm{kDa}}$ & 19.37 & 6.43 & 7.43 & 12.06 & 11.32 \\
\hline $\mathrm{CH}_{970 \mathrm{kDa}}$ & 19.37 & 4.87 & 6.81 & 6.18 & 9.31 \\
\hline Mean & 19.12 & 7.71 & 9.39 & 8.71 & \\
\hline $\mathrm{LSD}_{\mathrm{a}=0.05}$ & \multicolumn{5}{|c|}{$A=3.20$} \\
\hline
\end{tabular}

*not significant

LSD $_{\alpha 0.05}$ Least Significant Differences 
Table 2. Effect of different types and concentrations of chitosan on fresh and dry mass (g) and plant water contents $(\%)$ of petunia 'Prism White' in vitro

\begin{tabular}{|c|c|c|c|c|c|}
\hline \multirow{2}{*}{ Chitosan (A) } & \multicolumn{4}{|c|}{$\begin{array}{c}\text { Concentration (B) } \\
(\mathrm{ppm})\end{array}$} & \multirow{2}{*}{ Mean } \\
\hline & 0 & 10 & 15 & 20 & \\
\hline \multicolumn{6}{|c|}{ Fresh mass $(\mathrm{g})$} \\
\hline $\mathrm{CH}_{3.33 \mathrm{kDa}}$ & 0.89 & 0.87 & 0.98 & 0.97 & 0.93 \\
\hline $\mathrm{CH}_{8 \mathrm{kDa}}$ & 0.78 & 1.27 & 1.52 & 1.18 & 1.19 \\
\hline $\mathrm{CH}_{10 \mathrm{kDa}}$ & 0.78 & 0.85 & 1.35 & 0.70 & 0.92 \\
\hline $\mathrm{CH}_{970 \mathrm{kDa}}$ & 0.76 & 0.78 & 0.91 & 0.84 & 0.82 \\
\hline Mean & 0.80 & 0.94 & 1.19 & 0.92 & \\
\hline $\mathrm{LSD}_{\mathrm{a}=0.05}$ & \multicolumn{5}{|c|}{$A=0.31 \quad B=0.33 \quad A \times B=n s^{*}$} \\
\hline \multicolumn{6}{|c|}{ Dry mass $(\mathrm{g})$} \\
\hline $\mathrm{CH}_{3.33 \mathrm{kDa}}$ & 0.12 & 0.10 & 0.07 & 0.11 & 0.10 \\
\hline $\mathrm{CH}_{8 \mathrm{kD}} \mathrm{a}$ & 0.15 & 0.06 & 0.12 & 0.10 & 0.11 \\
\hline $\mathrm{CH}_{10 \mathrm{kDa}}$ & 0.10 & 0.08 & 0.05 & 0.09 & 0.08 \\
\hline $\mathrm{CH}_{970 \mathrm{kDa}}$ & 0.06 & 0.07 & 0.06 & 0.06 & 0.06 \\
\hline Mean & 0.11 & 0.08 & 0.08 & 0.09 & \\
\hline $\mathrm{LSD}_{\alpha=0.05}$ & \multicolumn{5}{|c|}{$A=0.04 \quad B=n s \quad A \times B=n s$} \\
\hline \multicolumn{6}{|c|}{ Water content (\%) } \\
\hline $\mathrm{CH}_{3.33 \mathrm{kDa}}$ & 75.5 & 75.5 & 90.8 & 85.6 & 81.8 \\
\hline $\mathrm{CH}_{8 \mathrm{kDa}}$ & 58.7 & 122.2 & 144.1 & 109.5 & 108.6 \\
\hline $\mathrm{CH}_{10 \mathrm{kDa}}$ & 65.1 & 75.5 & 131.2 & 57.1 & 82.2 \\
\hline $\mathrm{CH}_{970 \mathrm{kDa}}$ & 68.1 & 69.0 & 84.4 & 76.8 & 74.5 \\
\hline Mean & 66.8 & 85.5 & 112.6 & 82.2 & \\
\hline
\end{tabular}

*not significant

LSD $_{\alpha 0.05}$ Least Significant Differences

Table 3. The influence of different types of chitosan on morphological traits of petunia 'Prism White' under salt stress

\begin{tabular}{|c|c|c|c|c|c|c|}
\hline \multirow{3}{*}{ 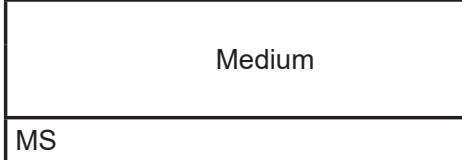 } & \multicolumn{6}{|c|}{ Morphological traits } \\
\hline & \multicolumn{2}{|c|}{ Shoot length $(\mathrm{cm})$} & \multicolumn{2}{|c|}{$\begin{array}{c}\text { Number of new shoots per } \\
\text { plant }\end{array}$} & \multicolumn{2}{|c|}{ Root length $(\mathrm{cm})$} \\
\hline & 5.23 & $a^{*}$ & 1.76 & $\mathrm{a}$ & 5.14 & a \\
\hline $\mathrm{MS}+100 \mathrm{mM} \mathrm{NaCl}$ & 1.62 & $\mathrm{~b}$ & 1.24 & a & 0.12 & b \\
\hline $\mathrm{MS}+100 \mathrm{mM} \mathrm{NaCl}+15 \mathrm{ppm} \mathrm{CH} \mathrm{CH}_{3.3 \mathrm{D}}$ & 1.71 & $\mathrm{~b}$ & 1.29 & $\mathrm{a}$ & 0.68 & $\mathrm{~b}$ \\
\hline $\mathrm{MS}+100 \mathrm{mM} \mathrm{NaCl}+15 \mathrm{ppm} \mathrm{CH}$ & 1.85 & $\mathrm{~b}$ & 1.35 & a & 1.15 & $a b$ \\
\hline $\mathrm{MS}+100 \mathrm{mM} \mathrm{NaCl}+15 \mathrm{ppm} \mathrm{CH} \mathrm{CH}_{10 \mathrm{D}}$ & 1.86 & $\mathrm{~b}$ & 1.47 & a & 0.24 & $\mathrm{~b}$ \\
\hline $\mathrm{MS}+100 \mathrm{mM} \mathrm{NaCl}+15 \mathrm{ppm} \mathrm{CH} \mathrm{CH}_{970 \mathrm{D}}$ & 1.93 & $\mathrm{~b}$ & 1.79 & a & 1.89 & $a b$ \\
\hline $\operatorname{LSD}_{a 0.05}$ & \multicolumn{2}{|c|}{2.17} & \multicolumn{2}{|c|}{1.89} & \multicolumn{2}{|c|}{3.98} \\
\hline
\end{tabular}

*Means in the same column followed by the same letters are not significantly different

$\mathrm{LSD}_{\alpha 0.05}$ Least Significant Differences

chanda and Garg, 2008; Khalid et al., 2015; Piwowarczyk et al., 2016], in order to determine the influence of salt stress on the plant growth, apart from measurements of shoot and root length, their weight should also be measured. Low growth coefficient may suggest the occurrence of adaptive processes for stress conditions within the plant. From the results of our study, it was determined that the addition of $100 \mathrm{mM} \mathrm{NaCl}$ to the MS medium caused a decrease in fresh and dry mass as well as plant water contents (by 56\%, 50\% and $71.2 \%$, respectively) compared with the control (Table 4). It was observed that the addition of chitosan to selective medium increased the growth of fresh and dry mass of petunia explants as well as plant water contents. However, these values did not differ statistically. In the presence of $10 \mathrm{kDa}$ chitosan and $970 \mathrm{kDa}$ chitosan in the concentration of $15 \mathrm{ppm}$ each in the selective medium, the percentage content of water in plant was twice as 
Table 4. The influence of different types of chitosan on morphological traits (fresh and dry mass), plant water content $(\%)$ and EC (\%) of petunia 'Prism White' under salt stress

\begin{tabular}{|c|c|c|c|c|c|c|}
\hline \multirow{2}{*}{ Medium } & \multicolumn{4}{|c|}{ Morphological traits } & \multirow{2}{*}{$\begin{array}{c}\text { Plant Water Content } \\
(\%)\end{array}$} & \multirow{2}{*}{$E C(\%)$} \\
\hline & \multicolumn{2}{|c|}{ Fresh mass $(\mathrm{g})$} & \multicolumn{2}{|c|}{ Dry mass (g) } & & \\
\hline MS & 1.16 & $a^{*}$ & 0.24 & a & 95.3 & 40.2 \\
\hline $\mathrm{MS}+100 \mathrm{mM} \mathrm{NaCl}$ & 0.51 & $\mathrm{~b}$ & 0.12 & a & 27.4 & 61.60 \\
\hline $\mathrm{MS}+100 \mathrm{mM} \mathrm{NaCl}+15 \mathrm{ppm} \mathrm{CH} \mathrm{CH}_{3.3 \mathrm{kD}}$ & 0.55 & $\mathrm{~b}$ & 0.05 & a & 45.9 & 54.9 \\
\hline $\mathrm{MS}+100 \mathrm{mM} \mathrm{NaCl}+15 \mathrm{ppm} \mathrm{C \textrm {CH } _ { 8 \mathrm { D } }}$ & 0.59 & $\mathrm{~b}$ & 0.07 & a & 47.1 & 52.9 \\
\hline $\mathrm{MS}+100 \mathrm{mM} \mathrm{NaCl}+15 \mathrm{ppm} \mathrm{C \textrm {CH } _ { 1 0 \mathrm { D } }}$ & 0.64 & $\mathrm{~b}$ & 0.06 & a & 54.6 & 52.1 \\
\hline $\mathrm{MS}+100 \mathrm{mM} \mathrm{NaCl}+15 \mathrm{ppm} \mathrm{CH}_{970 \mathrm{kD}}$ & 0.69 & $\mathrm{~b}$ & 0.07 & a & 58.8 & 50.2 \\
\hline Mean & \multicolumn{2}{|c|}{0.69} & \multicolumn{2}{|c|}{0.10} & 54.8 & 51.9 \\
\hline $\mathrm{LSD}_{\mathrm{a} 0.05}$ & \multicolumn{2}{|c|}{1.29} & \multicolumn{2}{|c|}{0.4} & & \\
\hline
\end{tabular}

${ }^{*}$ Means in the same column followed by the same letters are not significantly different

$\mathrm{LSD}_{\alpha 0.05}$ Least Significant Differences

high compared to explants from MS medium with addition of $100 \mathrm{mM} \mathrm{NaCl}$. The addition of $\mathrm{NaCl}$ to the MS medium also had a negative effect on electric conductivity (EC) in the plants (Table 4). However, it was observed that as the molecular weight of chitosan in the MS medium increased, the EC index decreased. Hence, the control petunia plants were characterized by a lower EC index $(40.2 \%)$. This is probably influenced by the higher growth rate of these explants in the initial phase of the culture.

These results are in agreement with those of Jabeen and Ahmad [2013] who reported that chitosan was an effective biostimulator to enhance safflower and sunflower seedling growth and plant tolerance to oxidative stress under salinity and could overcome severe stress through the reduction of enzyme activity caused by scavenging of ROS.

In this study, it was confirmed that chitosan can function as a plant growth stimulator for petunia micropropagation. The effect of chitosan on morphological traits of petunia was concentration and molecular weight dependent. However, it was found that chitosan in higher molecular weight (970 kDa) supplemented to solid MS medium can alleviate the effect of salinity stress by promoting shoot and root formation of petunia 'Prism White'. However, in order to better recognize and understand how chitosan may be related with salt tolerance, further and more precise research should be carried out.

\section{Acknowledgements}

This study was supported by the Polish Ministry of Science and Higher Education, within the project UPB 518-07-000-3176-01/18 ZUT

\section{REFERENCES}

1. Abdelhamid M.T., Sadak M.S.H., Schmidhalter U., El-Saady A.K.M. 2013. Interactive effects of salinity stress and nicotinamide on physiological and biochemical parameters of faba bean plant. Acta Biolo. Colomb., 18, 499-510.

2. Al-Tawaha A.R.M., Al-Ghzawi A.L.A. 2013. Effect of chitosan coating on seed germination and salt tolerance of lentil (Lens culinaris L.). Res. on Crops, 14(2), 489-491.

3. Angelova Z., Georgiev S., Ross W. 2006. Elicitation of plants. Biotechnol., 20, 72-83.

4. Ait Barka E., Eullaffroy P., Clément C., Vernet G. 2004. Chitosan improves development, and protects Vitis vinifera L. against Botrytis cinerea. Plant. Cell Rep., 22, 608-614.

5. Bartkowiak A. 2001. Binary polyelectrolyte microcapsules based on natural polysaccharides. Edt. PS Szczecin.

6. Bassuony F.M., Hassanein R.A., Baraka D.M., Khalil R.R. 2008. Physiological effects of nicotinamide and ascorbic acid on Zea mays plant grown under salinity stress. II-Changes in nitrogen constituent, protein profiles, protease enzyme and certain inorganic cations. Aust. J Appl. Sci., 2, 350-359.

7. Berenschot A.S., Zucchi M.I., Tulmann-Neto A., Quecini V. 2008. Mutagenesis in Petunia $\times$ hybrida Vilm. and isolation of a novel morphological mutant. Brazilian Journal of Plant Physiology 20, 16-27.

8. Dias A.M.A., Cortez A.R., Barsan M.M., Santos J.B., Brett C.M.A., De Sousa H.C. 2013. Development of greener multi-responsive chitosan biomaterials doped with biocompatible ammonium ionic liquids. ACS Sustainable Chem. Eng., 1(11), 1480-1492.

9. El Hadrami A., Adam L.R., El Hadrami I., Daayf F. 2010. Chitosan in plant protection. Mar. Drugs, 8, 968-987.

10. Gaswanto R., Syukur M., Purwoko B.S., Hidayat S.H. 2016. Induced mutation by gamma rays irra- 
diation to increase chilli resistance to begomovirus. Agrivita, J Agri. Sci., 38(1), 24-32.

11. Jabeen N., Ahmad R. 2013. The activity of antioxidant enzymes in response to salt stress in safflower (Carthamus tinctorius L.) and sunflower (Helianthus annuus L.) seedlings raised from seed treted with chitosan. J Sci. Food Agric., 93, 1699-1705.

12. Jones R.A. 1986. High salt tolerance potential in Lycopersicon species during germination. Euphytica, 35, 575-582.

13. Khalid H., Kumari M., Grover A., Nasim M. 2015. Salinity stress tolerance of Camelina investigated in vitro. Plant Sci., 46, 137-144.

14. Krupa-Małkiewicz M., Smolik B., Ostojski D., Sędzik M. 2015. Effect of ascorbic acid on morphological and biochemical parameters in tomato seedling exposure to salt stress. Environ. Protect. and Nat. Res., 24, 25-27.

15. Krupa-Małkiewicz M., Ostojski D., Sędzik M., Pelc J., Smolik B. 2016. Interactive effects of salinity stress with or without nicotinamide on physiological and biochemical parameters of tomato seedling. Foila Pomer. Univ. Technol. Stetin., Agric., Aliment., Pisc., Zootech., 326(38)2, 71-80.

16. Krupa-Małkiewicz M., Kosatka A., Smolik B., Sędzik B. 2017. Induced mutations through EMS treatment and in vitro screening for salt tolerance plant of Petunia $\times$ atkinsiana D.Don. Not. Bot. Horti. Agrobo., 45(1) DOI:10.15835/nbha45110578.

17. Lizárraga-Paulin E.G., Torres-Pacheco I., MorenoMartinez E., Miranda-Castro S.P. 2011. Chitosan application in maize (Zea mays) to counteract the effects of abiotic stress at seedling level. Afr. J Biotechnol., 10(34), 6439-6446.

18. Mahdavi B., Rahimi A. 2013. Seed priming with chitosan improves the germination and growth performance of ajowan (Carum copticum) under salt stress. Eursia J Biosci., 7, 69-76.

19. Manchanda G., Garg N. 2008. Salinity and its effects on the functional biology of legumes. Acta
Physiol. Plant., 30, 595-618.

20. Munns R. 2005. Genes and salt tolerance: bringing them together. New Phytologist, 167, 645-663.

21. Murashige T. Skoog F. 1962. A revised medium for rapid growth and bioassay with tobacco tissue culture. Physiol. Plantarum, 15, 473-497.

22. Obsuwan K., Sawangsri K., Ukong S., Uthairatanakij A. 2010a. Effects of chitosan concentration on in vitro growth of Dendrobium hybrid seedlings. Acta Hort. DOI: 10.17660/ActaHortic.2010.878.36.

23. Obsuwan K., Yoodee S., Uthairatanakij A. 2010b. Application of chitosan on in vitro growth of Rhynchostylis giganteaprotocorms and seedlings. Acta Hort. DOI:10.17660/ActaHortic.2010.878.35.

24. Piwowarczyk B., Tokarz K., Kamińska I. 2016. Responses of grass pea seedlings to salinity stress in in vitro culture conditions. Plant Cell Tiss. Organ. Cult., 124, 227-240.

25. Pongprayonn W., Roytrakul S., Pichayangkura R., Chadchawan S. 2013. The role of hydrogen peroxide in chitosan-induced resistance to osmotic stress in rice (Oryza sativa L.). Plant Growth Regul., 70, 159-173.

26. Queirós F., Fidalgo F., Santos I., Salema R. 2007. In vitro selection of salt tolerant cell lines in Solanum tuberosum L. Biol. Plant., 51, 728-734.

27. Rai M.K., Kalia R.K., Singh R., Gangola M.P., Dhawan A.K. 2010. Developing stress tolerant plants through in vitro selection - An overview of the recent progress. Environ. Exp. Bot., 71(1), 89-98.

28. Sadak M.Sh., Rady M.M., Badr N.M., Gaballah M.S. 2010. Increasing sunflower salt tolerance using nicotinamide and tocopherol. Int. J Academic Res., 2, 263-270.

29. Sopalun K., Thammasiri K., Ishikawa K. 2010. Effects of chitosan as the growth stimulator for Grammatophyllum speciosum in vitro culture. Int. J Innov. Res. Sci. Eng. Technol., 4(11), 828-830. 